\title{
What Remains of Transcranial Surgery in The Treatment of Pituitaryadenomas.
}

\author{
K.Bouaita ${ }^{1}$, Shabay.Z $Z^{2}$, N.Ioualalen ${ }^{3}$ \\ Department Of Neurosurgery, Hospital Ali Ait Idir, University Of Algeries, Algeria
}

\begin{abstract}
The objective of this work is to elaborate the role and the indications of the trans cranial surgery in the treatment of pituitary adenomas.This is a retrospective series of 29 cases of pituitary macroadenomas operated at Ali Ait Idir hospital from 2010 to 2015. Mean age of the patients was 35 years. The sex ratio was 17 females / 12males. The time to consultation was between 11 months and 2 years after onset of symptoms. Clinical signs were predominantlyopto-chiasmatic syndrome with blurred vision in $95 \%$ of cases. 10patients hormonal imbalance syndrome, a cavernous sinus syndromewith involvement ofunilateral third cranial nerve III in 04 patients (drooping of the upper eyelid). A syndrome of intracranial hypertension in patients with an incomplete frontal lobe syndrome 04pateints and generalized tonic-clonic seizures in two patients.All patients had preoperative MRI. Twenty-nine patients underwent transcranial surgery, the most common approachin all patients (100\% of cases) is the frontotemporal approachwith opening of the Sylvian valley. Ten patients had already been operated at first by endoscopic endonasalapproach including five patients who were already operated twice transsphenoidal endoscopic approach.Improvementin visual function in $54.7 \%$ of cases, remained unchanged in $34.5 \%$ of cases and worsened in $13.8 \%$ of patients.
\end{abstract}

Keywords: endocrine disorders, pituitary adenoma, , visual function, total resection transcranial surgery.

\section{Introduction}

Since the first description of acromegaly by PIERRE MARIE in 1886 andthe individualisation of its origin as an anterior hypophysis tumor (1), many things have changed in the field of pituitary adenomas especially in the diagnostic and therapeutic management. First by the re-introduction of trans-sphenoidal approach by Gérard GUIOT in (1958) under the image intensifier and there was additional finesse provided by the use of the microscope introduced by Jules HARDY to achieve a microscopic transsphenoidal surgery (2-3). With the development of technology and the introduction of minimally invasive surgery, a pure endoscopic transsphenoidal technique was introduced in 1997, JHO reported a series of 50 cases of which 46 were treated with this approach (4-5-6). Paolo Cappabianca and Enrico DeDevitiis are among the first to report their experience in this field,by introducing the term « functional endoscopic pituitary surgery » (4-5-6).

Transcranial surgery was the first surgical approach used historically for the surgical treatment of pituitary tumors. Horsley described it in 1906, several cases operated successfully intracranially by sub-frontal approach(10). Cushing standardised the technique with a median direct sub-frontal approach.

Gazi Yaşargil demonstrated the benefits of transcranial surgery for sellar and suprasellar tumors using pterional approach minimizing brain retraction after opening the Sylvian fissure and arachnoid of the basal cisterns (2).

The progress of endocrinology, also changed the therapeutic attitude to the pituitary adenomas. The initial distinction between secreting adenoma and non-secreting adenoma, through endocrinological classification is more precise. Finally, a fundamental contribution is the development of modern imaging: CT and especially MRI, made accessible to therapists as a reliable and harmless imaging modality, enabling to address therapeutic indications which only take into accountthe disease itself and nothing else.The purpose of the pituitary surgery is the complete removal of the adenoma, and decompression of the optical canals. Currently the endoscopic endonasaltranssphenoidal approach is the most widely used in the surgical treatment of pituitary adenomas. Rare cases nevertheless may require a transcranial approach. In this series, we will specify the role and the indication of the trans cranial surgery in the treatment of pituitary adenomas.

\section{II. patients and methodes}

This is a retrospective study of 29 patients with pituitary macroadenomasoperated at Ali aitIdir hospital from 2010-2015.Mean age of the patients was 35 years. The sex ratio was $17 \mathrm{females} / 12 \mathrm{males}$. The time to consultation was between 11 months and 2 years after onset of symptoms. All the patients were investigated in Neurosurgical and Endocrinological Departments. Visual acuity and visual field defects andcartographic fields were done by the department of ophthalmology in pre and post-operatively in eachvisit.Hormonal investigations include T4, TSH, blood Cortisol, follicle-stimulatinghormone (FSH), luteinisinghormone (LH), prolactine and Growth hormone $(\mathrm{GH})$ for all patients pre and post-operatively. 
Clinical signs were dominated by opto-chiasmaticsyndrome with visualdeficits in $95 \%$ of patients. Diminution of visualacuitywas the major symptom.It was unilateral in $40 \%$ and bilateral in $60 \%$ of patients. We noted a high frequency of blindness (40\%). Visual field deficits were observed in lesionscompressing the optic chiasma with retro chiasmaticextension (classicbitemporal in 13 patients). Endocrinal syndrome in10patients with amenorrhea - galactorrhea in females, cushing syndromeand diabetes insipidus.Cavernous sinus syndrome with unilateral IIIrd cranialnerve palsy in 04 patients (drooping of upper eyelid).

Intracranial hypertensionsyndrome(headaches and vomitting and on fundoscopy: bilateral papillary œdema) in patients withincompletefrontal lobe syndrome 04pateints.tonico-clonicgeneralised seizures in two patients.

All patients had an MRI preoperativelyin precise sagittal, coronal and frontal cuts; the form of the adenoma (hour-glass adenoma), size of tumor, the extent of the tumor and its close relationship with both supraclinoid internal carotid arteries, the lateral extent of the lesion to the two cavernous sinuses and sub-frontal region.

The magnetic resonance imaging in coronal cuts can show the retro chiasmal extension of the tumor and towards the foramen of Monro which is responsible for a bi ventricular hydrocephalus. In addition, it shows the extension of the lesion in the sphenoid sinus to the clivus.

The CT scan is essential especially in coronal, axial cuts.It retains a significant interest in the study of the sphenoid sinus, morphology, the existence of any intra-sinus walls or pathology of the mucosa (importantly endoscopic endonasal approach).In the immediate postoperative period we performed a CT scan axial cuts to eliminate a surgical cavity hematoma or cerebral edema, postoperative MRI 3-6 months would be repeated annually there after. Eighteen of the 29 cases had giant adenomas with maximum tumor diameter exceeding 4 $\mathrm{cm}$. Hydrocephalus was observed in 4 patients, two of which had a ventricular peritoneal shunt.

Twenty-nine patients were operated by transcranial route, the most common approach in all patients (100\% of cases) is the frontotemporal approach with opening of the Sylvian valley.

The left frontotemporal approach was used in 05 patients (in 17.24\% of cases), in whichthere was a tumor extension laterally to the left and a significant decline in visual acuity of the left side.Ten patients had already been operated atthe first stage by endoscopic endonasa lincluding five patients who were already operated twice bytranssphenoidal endoscopic approach.

These last patients had intra and suprasellar macroadenoma with a lower extension in the sphenoid sinus, the consistency of the tumor during transsphenoidal surgery was one of the factors that has limited the quality of resection, and the hourglass or figure eight shape of the adenoma.Nineteen patients were operated intracranially directly because of the importance and extent of the lesion especially lateral to the cavernous sinus and its extension in front and towards the clivus, macroadenoma with a small sella turcica, hourglass adenoma below and above the diaphragm.

\section{Results}

$\square$ Sugical Results:The extent of tumor excision was evaluated immediate postoperatively by a brain ct-scan and a brain MRI after 3 months post operatively.Surgical excision was complete in 10patients ( $34,5 \%$ of patients),subtotal in 13 patients (44,8\% of patients) and partial in 6patients ( $20,7 \%$ of patients),

Resection was considered subtotal if a tumor nodule had been left in place, either in the optic canal or adjacent the internal carotid artery, the pituitary stalk or adjacent the optic chiasm because of adhesions.

$\Delta$ Visual Results: The visual function analysis was first performed in the immediate postoperative period looking for a visual improvement or worsening by the neurosurgeon himself, followedby the ophthalmologistin the short and long term.

A visual function improvement was noted in $54.7 \%$ of patients, remained unchanged in $34.5 \%$ and worsened in $13.8 \%$ of patients. The visual field defect was improved after surgery in ten patients.

$\Delta$ Endocrine Results:The endocrine evaluation analysis in the immediate postoperative periodfound diabetes insipidus in eight patients, pan-hypopituitarism in six patients who needed replacement therapy postoperatoively.04 patients are still under treatment with Minirin for permanent diabetes insipidus.

All patients are monitored regularly by the Department of Endocrinology clinically, radiologically and by regular hormonal analysis.

The different types of adenomas found in our series; Chromophobic or non secretingadenomain nineteen patients $(65.5 \%)$, prolactinomas in 6 patients (20.5\% of cases), corticotrophic adenoma in 04 patients (14\% of cases).

\ Postoperative Follow up: All patients were regularly followed up clinically and radiologically by the neurosurgeon, endocrinologist and ophthalmologist.

The follow-up period ranged from a 1 to 5 years. All patients with residual tumor underwent radiological examinations especially brain MRI to assess the evolutionary potential of the lesion and to act accordingly. 
4 cases of tumor recurrence within an average of 2 years were seen. They posed therapeutic choice difficulties. One patient was operated by endoscopic endonasaltranssphenoidal approach as the residual tumor was intrasellar.The other three patients underwent radiotherapy. For patients in whomresectionqualitywassatisfactory, an MRI wasperformedevery six months the first year, everyyear for 5 years, and everytwoyearsthereafter.

$\square$ Mortality And Morbidity Postoperative morbidity was dominated by;

a patient had aIIIrd cranial nerve palsy which improved partially after a long follow-up 16 months.

- Delayed cerebrospinal rhinorrhea that appeared in a patient operated for a macro-prolactinoma one year after the intervention by transcranial approach and bromocriptine as medical treatment, which was repaired by endoscopic endonasaltranssphenoidal approach.

- Transient diabetes insipidus in 06 patients which disappeared after an average of 4-5days,

-Eight patients developed hypopituitarism in immediate postoperative period needing replacement therapy.

Postoperative mortality was zero.

\section{Discussion}

According to the different series in the literature, less than $10 \%$ of pituitary tumors require trans-cranial surgery. The main reason for this decline are the advancedtechniques and low mortality -morbidity after this surgery.

The results of transcranial pituitary surgery in literature namely the recovery of visual function, correction of hormonal hypersecretion or the quality of tumor removal and improved preoperative pituitary deficit are not homogeneous in comparison to the results of transsphenoidal surgery in the recent decades.

In large series of patients, it appears that one can have the best functional results after transcranial resection (7-8-9-10), as in the case of a series of 300 patients reported by Patterson et al (11). The normalization of vision has been reported retrospectively in $17 \%$ of patients after transsphenoidal procedures $(n=70)$ and $45 \%$ of patients after transcranial surgery $(\mathrm{n}=94)$. After all, there are several authors who report similar or better results with the transsphenoidal approach in terms of the rate of recovery of visual functions; these results are similar and identical with our results regarding transcranial surgery for pituitary adenomas(11-12-13-14).

Fahlbusch et al,comparing the trans-sphenoidal surgery with transcranial surgery,reported a normalization and improvement of visual function in $80 \%$ and $48 \%$ respectively,for pituitary adenomas (3).Visual acuity and visual fields deteriorated in $2 \%$ of cases in the group operated transsphenoidally compared to $22 \%$ of cases in the group of transcranial surgery. At all times there is no doubt that the risk of postoperative pituitary hormonal dysfunction and anterior pituitaryfailureis more significant in the Transcranial than transsphenoidal approaches $(15,16)$.

On a retrospective series of 155 patients with non-secreting pituitary adenomas reported by WichersRother et al, The corticotrophic axis and the thyroid axis were significantly altered after transcranial surgery than after transsphenoidal surgery atlong term follow up (17). As regards to the quality and extent of tumor resection, the series of Mortini et al. (9), concluded that $40 \%$ of cases operated by transsphenoidal approach (85 patients) underwent complete resection versus $42 \%$ for intracranial surgery (26 patients).

Mortiniet al have reported that there was a visual improvement in 55\% of cases operated by transsphenoidal approach versus $74.5 \%$ of cases by transcranial pathway (9). The mortality rate for a transsphenoidal procedure in experienced hands should be less than $1 \%$. In addition the literature suggests an overall morbidity lower $10 \%$. These data have encouraged more and more surgeons to consider the pituitary transsphenoidal approach as a standard for almost all pituitary adenomas (8-18-19-20).However, there are still a number of different indications for transcranial approach for pituitary adenomas (3-10-21-22-23-24-25-26), one of the indications is the giant adenoma or with wide intra-sellaire component in combination with a smallsellaturcica.

Some surgeons advocate a trans-cranial first for hourglass shapedand sub diaphragmatic adenomas, these tumors perforate the diaphragm and do not present a clear capsule. We compared our indications and our experience with transcranial surgery for pituitary adenomas with those in the literature, We preferred transcranial approach for 3 patients with chromophobicmacroadenoma with a significant suprasellar extension on a small sellaturcica.

We operated 10 adenomas with a lateral extension to the supra-clinoidalinternal carotid artery where 3 patients had already been operated by endoscopic endonasaltranssphenoidal approach leaving in place a part of the tumor that progressed after a follow-up 12 months. The giant adenomas with an asymmetrical lateral extension, makes them difficult to excise under endoscope despite the availability of endoscope $30^{\circ}$ and $45^{\circ}$ angle because of the risk of trauma to vessels and the inability to control bleeding as a consequence.

Some authors have discussed the use of intraoperative MRI after excision of the adenoma by transsphenoidal approach to determine the size and extent of residual tumor during surgery and then use a transcranial approach at the same sitting if the residue is significant (27). The extension of the adenoma in the 
frontal region is an indication for the transcranial approach but sometimes this lesion can be resected by extended endoscopictranssphenoidaltransplanum approach.

Sometimes this tumor extension is asymmetrical to one sidelaterally,ensheathed with the A1 segment of the anterior cerebral artery, safe tumor resection becomes difficult using thetranssphenoidal route despite the availability of endoscopes with angles and therefore we propose the patient be operated by a transcranial route at a second sitting.On the contrary, some authors propose operating at the same sitting with a second approach which is the transcranial route. We had 05 patients operated with an adenoma in eight or hourglass shape with a double component supra and sub-diaphragmatic, by endoscopic endonasaltranssphenoidal technique and at a second time by transcranial technique where the quality of resection was limited to the sub diaphragmatictumor portion.It is well known that the consistency of the tumor plays an important role in achievingthe maximum possible tumor resection by transsphenoidalapproach (20-28). For example a giant adenoma may be amenable to total resection when the tumor is soft and easily removed by aspiration. On the other hand fibroids (representing $5-7.5 \%$ of large pituitary adenomas), are difficult to reduce despite using dissectors, curettes, ultrasonic aspiration. Inadequateexcision might deserve a transcranial approach, but it is not an absolute indication (10-2028)

Snow et al have found that T2 weighted MRI can be a good preoperative predictor for solid tumors to determine the surgical approach (3). The three standard transcranial approaches for pituitary adenomas are pterional approach (frontotemporal) and variants of sub-frontal approach, as inter hemispheric fronto-basal approach and Sub temporal approach. In addition to these standard approaches and frequently used in the suprasellar region, there are other specific transcranial approaches used only in rare cases, for example, the orbitofrontal zygomatic or trans-callousal inter hemispheric approach.In our series we used thefronto-temporal approach for all adenomas. The fronto-pterional approach is the most frequently used approach. It enables the control the midline, andwork in the inter optic space.Dissection of the optic tract, carotid arteries and its collaterals, is done carefully.

\section{*Complications}

Most potential complications in Transcranial pituitary surgerydo not differ much from common complications encountered in general transcranial neurosurgery; local infection at the craniotomy site, a collection of CSF in subcutaneous space or the occurrence of meningitis, a consecutive atrophy of the temporalis muscle, deterioration of functions of the cranial nerves, cerebral ischemia.Although the technical progress that has emerged over the past three decades, reduces morbidity and mortality associated with transcranial and also pituitary surgery. Symon and Jakubowski have reported a mortality rate of $0.99 \%$ for small adenomas and about $18 \%$ mortality for giant adenomas (3).

Van Lindert et al had a mortality rate of $5.7 \%$ with Transcranial pituitary surgery in a series that included all sizes of pituitary adenomas (3). Some authors have reported that the mortality rate for giant adenomas after transcranial surgery ranging from 4.6 to $18.7 \%$ of cases, while the morbidity rate is 10.4 to $23.2 \%$ of cases. (3-7-12-21-29)Recent studies indicate that the minor surgical morbidity can be high after transcranial surgery in $75 \%$ of cases for giant adenomas. Other complications of pituitary transcranial surgery; endocrine disorders postoperatively in connection with a disturbance or hormonal deficiency is more common in this surgery compared to the transsphenoidal surgery. In the series of Nomikos et al of 721 patients with nonfunctioning pituitary adenomas, $15 \%$ of patients showed a new hypopituitarism after transcranial surgery versus $1.4 \%$ of patients after transsphenoidal surgery. (30)

Taking into account that preoperatively, there were already some degree of hypopituitarism in $85 \%$ of patients in the group of transsphenoidal surgery, and $86.3 \%$ in the group of transcranial surgery (30).In 19.6\% of the group of transsphenoidal surgery, patients resumed normal postoperative pituitary function, compared with none after transcranial surgery.The improvement of pituitary function was found in $30.1 \%$ of patients in the group of transsphenoidal surgery compared to only $11,3 \%$ in the group of transcranial surgery.Pituitary deficit remained unchanged at $48.9 \%$ in the group of transsphenoidal surgery compared to $73.7 \%$ in the group of transcranial surgery (30). Diabetes insipidus, as a result of a manipulation of the pituitary stalk or hypothalamus is also more common in transcranial thantranssphenoidal surgery.

Nevertheless, transient diabetes insipidus is a common event in the immediate postoperative period after transcranial pituitary surgery (31). In a series of 721 patients with pituitary non secretingadenoma, transient polyuria with low urinary density occurred up to $34 \%$ of cases (30). However, permanent diabetes insipidus finally occurred in $3.2 \%$ of patients in the transcranialsurgery group3compared with $0.3 \%$ of patients in the group of transsphenoidal surgery (30). Other metabolic complication were hyponatremia $(<132 \mathrm{mmol})$ as a result of water retention associated with inappropriate ADH secretion is also commonly seen in the postoperative period, mostly lasts a few days after the procedure. Visual impairment is a complication that is not uncommon in the pituitary transcranial surgery, the main cause of postoperative visual deterioration is the loss of blood supply of optic canals (deforming the small feeder vessels of the optic nerves and optic chiasm) after suprasellar 
dissection of tumors (32) Loss of micro vasculature of the perforating arteries can also cause postoperative hypothalamic trauma, which is one of the most specific complications of transcranialsurgery for pituitary tumors.

Third (III)rd cranial nerve palsy is a common complication after transcranial supra-sellar tumors surgery- especially invasive para-sellar tumors involving the cavernous sinus (25)

Figures and Tables:

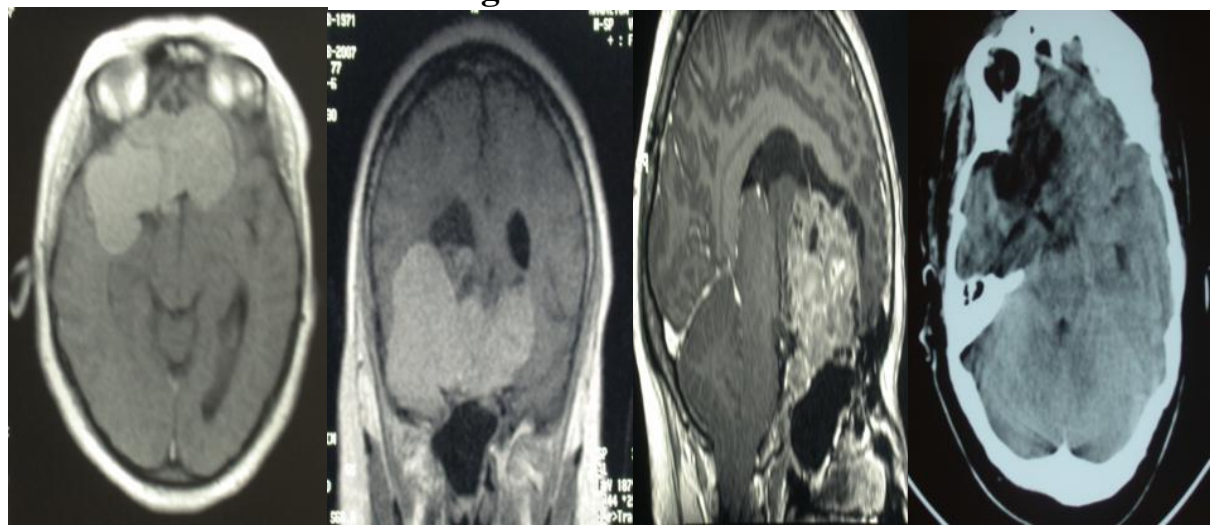

Fig1 :-MRIimages in saittal,coronal and axial cuts showing a giant adenomawith significant lateral extension to the right and towards the third ventricle.

- postoperative ct-scanimage showing the a satifsactory extent of tumor excision.
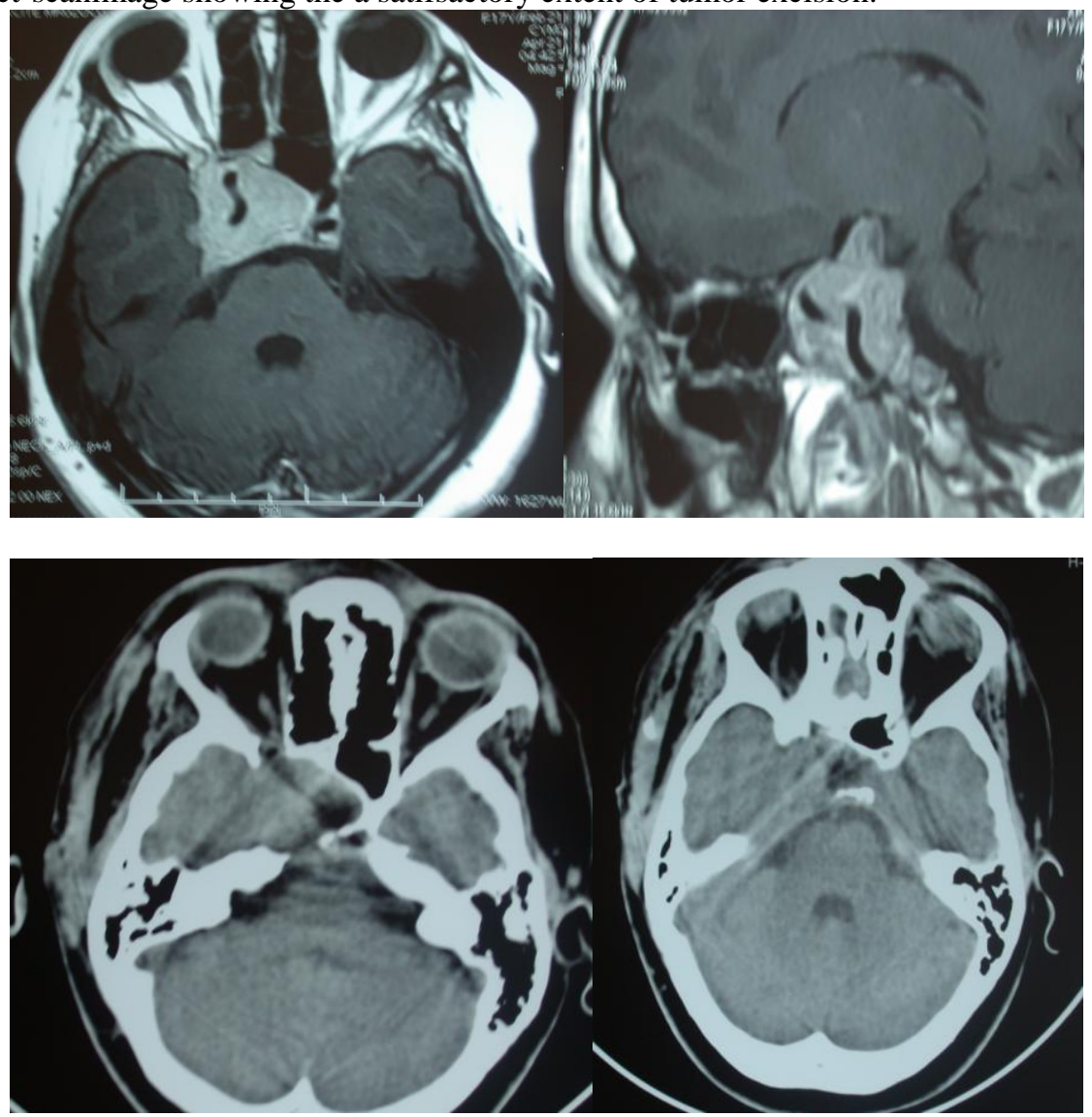

Fig2 :-imagesMRIin saittal and axial cuts showing a giant adenomawith lateral extension ( the internal carotid artery appears to be encased by the tumor) right and below is in the sphenoidal sinus. 

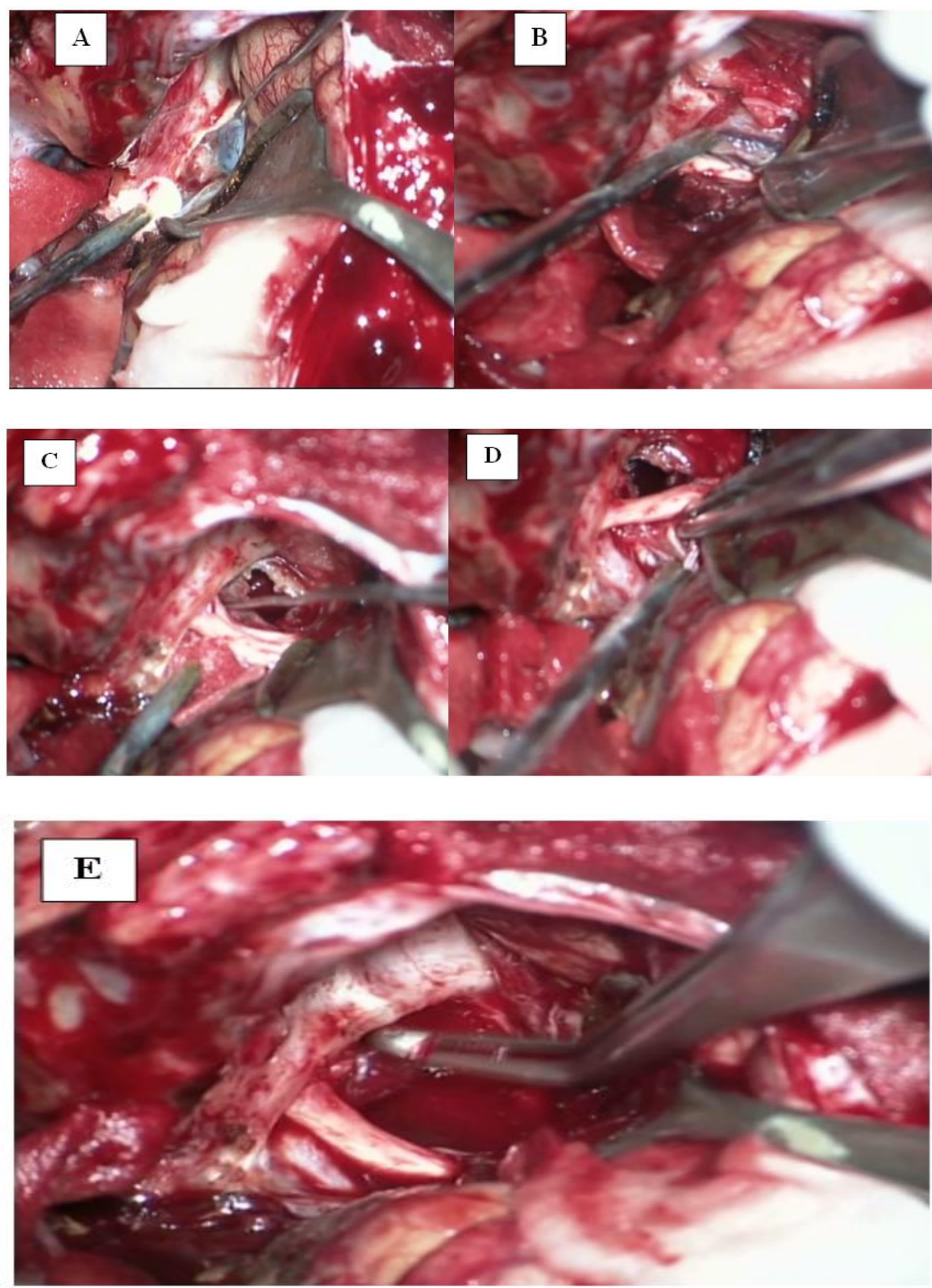

Fig3: peroperative images :

A : libération du nerf optique gauche. B- libération du nerf optique droit. C : adenoma resection in the inter optic space. D :'adenoma excision in the right inter optico-carotidspace. $\mathbf{E}$ : adenoma excision.

\section{Conclusion}

In the surgical treatment of pituitary adenomas, the transsphenoidal surgery remains the most used approach by neurosurgeons, but transcranial surgery may be required in about $5 \%$ of cases according to the literature.In general, a transcranial approach should be considered when the size of the adenoma is large (giant adenoma) with lateral extension towards the cavernous sinus, anteriorly in the sub-frontal region or backwards towards the clivus.The most frequently used approach in this surgery is pterional or frontotemporal, unilateral sub-frontal and other approaches.The current literature focuses on outcomes and complications after transsphenoidal surgery with and without use of endoscopy and unfortunately only few recent data are actually available on results of transcranial procedures for pituitary adenomas. Generally in front of a giantadenomathe strategy to reduce the volume of the tumorfollowed by adjuvant radiotherapyshouldoffer the best resultswith regard to tumor control and patient safety. 


\section{References}

[1]. Buchfelder M.Treatment of pituitary tumors: surgery. Endocrine. 2005 Oct;28(1):67-75.

[2]. Hardy J.History of pituitarysurgery.Neurochirurgie. 2010 Aug;56(4):358-62

[3]. Buchfelder M, Kreutzer J.Transcranialsurgery for pituitary adenomas.Pituitary.2008;11(4):375-84.

[4]. Cappabianca P, Cavallo LM, de Divitiis O, de Angelis M, Chiaramonte C, Solari D.Endoscopic Endonasal Extended Approaches for the Management of Large Pituitary Adenomas.NeurosurgClin N Am. 2015 Jul;26(3):323-31

[5]. Solari D, Cavallo LM, CappabiancaP.Surgical approach to pituitarytumors.HandbClin Neurol. 2014;124:291-301.

[6]. Koutourousiou M, Gardner PA, Fernandez-Miranda JC, Paluzzi A, Wang EW, Snyderman CH.Endoscopic endonasalsurgery for giant pituitary adenomas: advantages and limitations.JNeurosurg. 2013 Mar;118(3):621-31.

[7]. Pratheesh R, Rajaratnam S, Prabhu K, Mani SE, Chacko G, Chacko AG. The current role of transcranialsurgery in the management of pituitaryadenomas.Pituitary. $2013 \mathrm{Dec} ; 16(4): 419-34$.

[8]. Loyo-Varela M, Herrada-Pineda T, Revilla-Pacheco F, Manrique-Guzman S.Pituitary tumor surgery: review of 3004 cases. WorldNeurosurg. 2013 Feb;79(2):331-6.

[9]. Mortini P, Barzaghi R, Losa M, Boari N, Giovanelli M.Surgical treatment of giant pituitary adenomas: strategies and results in a series of 95 consecutive patients.Neurosurgery. 2007 Jun;60(6):993-1002.

[10]. Couldwell WT.Transsphenoidaland :transcranialsurgery for pituitary adenomas.J Neurooncol. 2004 Aug-Sep;69(1-3):237-56.

[11]. Musleh W, Sonabend AM, LesniakMS:Role of craniotomy in the management of pituitary adenomas and sellar/ parasellar tumors. Expert Rev Anticancer Ther ,2006, 6:79-83

[12]. Müslüman AM, Cansever T, Yılmaz A, Kanat A, Oba E, Çavuşoğlu H, Sirinoğlu D, Aydın Y.

[13]. Surgical results of large and giant pituitary adenomas with special consideration of ophthalmologic outcomes. World Neurosurg. 2011 Jul-Aug;76(1-2):141-8.

[14]. Murad MH, Fernández-Balsells MM, Barwise A, Gallegos-Orozco JF, Paul A, Lane MA, Lampropulos JF, Natividad I, PeresteloPérez L, Ponce de León-Lovatón PG, Albuquerque FN, Carey J, Erwin PJ, Montori VM. Outcomes of surgical treatment for nonfunctioning pituitary adenomas: a systematic review and meta-analysis.ClinEndocrinol (Oxf). 2010 Dec;73(6):777-91.

[15]. Zhang F, Chen J, Lu Y, Ding X. Manifestation, management and outcome of subclinical pituitary adenomaapoplexy.JClinNeurosci. 2009 Oct;16(10):1273-5.

[16]. Mortini P, Barzaghi R, Losa M, Boari N, Giovanelli M :Surgical treatment of giant pituitary adenomas: strategies and results in a series of 95 consecutive patients. Neurosurgery,2007, 60:993-1002

[17]. Webb SM, Rigla M, Wa"gner A, Oliver B, BartumeusF :Recovery of hypopituitarism after neurosurgical treatment of pituitary adenomas. J ClinEndocrinolMetab ,1999, 84:3696-3700

[18]. Wichers-Rother M, Hoven S, Kristof RA, Bliesener N, Stoffel- Wagner B : Non-functioning pituitary adenomas: endocrinological and clinical outcome after transsphenoidal and transcranial surgery. ExpClinEndocrinol Diabetes 2004, 112:323-327

[19]. Komotar RJ, Starke RM, Raper DM, Anand VK, Schwartz TH. Endoscopic endonasal compared with microscopic transsphenoidal and open transcranial resection of giant pituitary adenomas.Pituitary. 2012 Jun;15(2):150-9.

[20]. Leung GK, Law HY, Hung KN, Fan YW, LuiWM.Combined simultaneous transcranial and transsphenoidal resection of large-togiant pituitary adenomas.ActaNeurochir (Wien). 2011 Jul;153(7):1401-8.

[21]. D'Ambrosio AL, Syed ON, Grobelny BT, Freda PU, Wardlaw S, Bruce JN.Simultaneous above and below approach to giant pituitary adenomas: surgical strategies and long-term follow-up.Pituitary. 2009;12(3):217-25.

[22]. Guo F, Song L, Bai J, Zhao P, Sun H, Liu X, Yang B, Wang S.Successful treatment for giant pituitary adenomas through diverse transcranial approaches in a series of 15 consecutive patients.=ClinNeurolNeurosurg. 2012 Sep;114(7):885-90.

[23]. Spallone A, Vidal RV, Gonzales JG.Transcranial approach to pituitary adenomas invading the cavernous sinus: A modification of the classical technique to be used in a low-technology environment.SurgNeurol Int. $2010 \mathrm{Jul} 1 ; 1$.

[24]. Matsuyama J, Kawase T, Yoshida K, Hasegawa M, Hirose Y, Nagahisa S, Watanabe S, Sano H :Management of large and giant pituitary adenomas with suprasellarextensions. Asian J Neurosurg. 2010 Jan;5(1):48-53..

[25]. Buchfelder M.Management of aggressive pituitary adenomas: current treatment strategies.Pituitary. 2009;12(3):256-60.

[26]. Spallone A, Gonzàlez-Gonzàlez JL, Mostes de Oca F, Verdial-Vidal R.Pituitary adenomas invading the cavernous sinus. Transcranialtranscavernous approach].Neurocirugia (Astur). 2007 Aug;18(4):294-300.

[27]. Maartens NF, Kaye AH.Role of transcranial approaches in the treatment of sellar and suprasellarlesions.FrontHorm Res. 2006;34:128. Review.

[28]. 149

[29]. Berkmann S, Schlaffer S, Nimsky C, Fahlbusch R, BuchfelderM.Intraoperative high-field MRI for transsphenoidal reoperations of nonfunctioning pituitary adenoma.JNeurosurg. 2014 Nov;121(5):1166-75.

[30]. Leung GK, Yuen MM, Chow WS, Tse PY, Lui WM. An endoscopic modification of the simultaneous 'above and below' approach to large pituitaryadenomas.Pituitary. 2012 Jun;15(2):237-41.

[31]. Garibi J, Pomposo I, Villar G, GaztambideS :Giant pituitary adenomas: clinical characteristics and surgical results. Br J Neurosurg 2002, 16:133-139

[32]. Nomikos P, Ladar C, Fahlbusch R, Buchfelder M: Impact of primary surgery on pituitary function in patients with nonfunctioning pituitary adenomas - a study on 721 patients. ActaNeurochir (Wien) 2004 146:27-35

[33]. Mortini P, Barzaghi R, Losa M, Boari N, Giovanelli M :Surgical treatment of giant pituitary adenomas: strategies and results in a series of 95 consecutive patients. Neurosurgery 2007,60:993-1002 .

[34]. Maartens NF, Kaye AH :Role of transcranial approaches in the treatment of sellar and suprasellar lesions. Front Horm Res 2006,34:1-28

[35]. CouldwellWT :Transsphenoidal and transcranial surgery for pituitary adenomas. J Neurooncol 2004,69:237-256

[36]. Gupta R, Sharma A, Vaishya R, TandonM.Ischemic complications after pituitarysurgery: a report of two cases.J NeurolSurg A Cent EurNeurosurg. 2013 Dec;74 Suppl 1:e119-23.

[37]. Buchfelder M, SchlafferS.Surgical treatment of pituitarytumours.Best Pract Res ClinEndocrinolMetab. 2009 Oct;23(5):677-92.

[38]. Musleh W, Sonabend AM, LesniakMS.Role of craniotomy in the management of pituitary adenomas and sellar/parasellartumors.Expert Rev Anticancer Ther. 2006 Sep;6Suppl 9:S79-83.

[39]. 147 .

[40]. Youssef AS, Agazzi S, van LoverenHR.Transcranialsurgery for pituitary adenomas.Neurosurgery. 2005 Jul;57(1 Suppl):168-75.

[41]. Liu JK, Weiss MH, Couldwell WT. Surgical approaches to pituitary tumors.NeurosurgClin N Am. 2003 Jan;14(1):93-107. Review

[42]. Garibi J, Pomposo I, Villar G, Gaztambide S (2002) Giant pituitary adenomas: clinical characteristics and surgical results. Br J Neurosurg 16:133-139

[43]. Patterson LH The role of transcranial surgery in the management of pituitary adenoma.ActaNeurochir Wien,1996, 65(Suppl):16-17 